\title{
Running Speed Alters the Frequency of Hippocampal Gamma Oscillations
}

\author{
Omar J. Ahmed ${ }^{1}$ and Mayank R. Mehta ${ }^{2}$ \\ ${ }^{1}$ Department of Neuroscience, Brown University, Providence, Rhode Island 02912, and ${ }^{2}$ Keck Center for Neurophysics, Department of Physics and \\ Astronomy, Department of Neurology, Department of Neurobiology, Integrative Center for Learning and Memory, University of California, Los Angeles, \\ Los Angeles, California 90095
}

Successful spatial navigation is thought to employ a combination of at least two strategies: the following of landmark cues and path integration. Path integration requires that the brain use the speed and direction of movement in a meaningful way to continuously compute the position of the animal. Indeed, the running speed of rats modulates both the firing rate of neurons and the spectral properties of low frequency, theta oscillations seen in the local field potential (LFP) of the hippocampus, a region important for spatial memory formation. Higher frequency, gamma-band LFP oscillations are usually associated with decision-making, increased attention, and improved reaction times. Here, we show that increased running speed is accompanied by large, systematic increases in the frequency of hippocampal CA1 network oscillations spanning the entire gamma range $(30-120 \mathrm{~Hz})$ and beyond. These speed-dependent changes in frequency are seen on both linear tracks and two-dimensional platforms, and are thus independent of the behavioral task. Synchrony between anatomically distant CA1 regions also shifts to higher gamma frequencies as running speed increases. The changes in frequency are strongly correlated with changes in the firing rates of individual interneurons, consistent with models of gamma generation. Our results suggest that as a rat runs faster, there are faster gamma frequency transitions between sequential place cell-assemblies. This may help to preserve the spatial specificity of place cells and spatial memories at vastly different running speeds.

\section{Introduction}

Most species use a combination of external (allothetic) and internal (idiothetic) cues to navigate. Dead reckoning, inertial navigation, and path integration refer to navigational strategies dependent upon internally generated cues (Barlow, 1964; McNaughton et al., 1996, 2006; Whishaw et al., 1997). Path integration necessitates that the brain continuously track the direction and speed of movement to calculate the current position of the animal.

What are the neural correlates of direction and speed? In rodents, neurons encoding head direction have been found in the postsubiculum (Taube et al., 1990a,b), lateral and anterior dorsal thalamus (Mizumori and Williams, 1993; Taube, 1995), medial entorhinal cortex (Sargolini et al., 2006), and several other cortical and subcortical structures important for the encoding of spatial information (Taube, 2007). In the hippocampus, a structure known to be of fundamental importance for spatial memory and

Received Oct. 10, 2011; revised March 16, 2012; accepted April 9, 2012.

Author contributions: 0.J.A. and M.R.M. designed research; 0 .J.A. performed research; 0 .J.A. contributed unpublished reagents/analytic tools; 0.J.A. analyzed data; 0.J.A. and M.R.M. wrote the paper.

This work was supported by an NIMH Predoctoral Grant (MH081477) awarded to 0.J.A. and grants from the W. M. Keck foundation, the Whitehall foundation, a NARSAD Young Investigator Award, NSF Career Award\#0969034, and NIH/CRCNS \#1-R01-MH-092925-01 to M.R.M. We wish to thank Dr. James Knierim for his helpful comments on a previous version of this manuscript, and also Lucas Santos, James McFarland, Ammar Shaikhouni, Luk Chong Yeung, Arvind Kumar, Annie van Beuningen, Alison Boyd, Ethan Brown, Vivek Buch, Vivek Chellappa, Joshua Lai, Lyle Muller, Samuel Reiter, Hank Schilling, and Valerie Yanofsky.

Correspondence should be addressed to $0 \mathrm{mar}$ J. Ahmed at his present address: Department of Neurology, Massachusetts General Hospital, 55 Fruit Street, Thier 423, Boston, MA 02114. E-mail: omar.j.ahmed@gmail.com.

DOI:10.1523/JNEUROSCI.5110-11.2012

Copyright $\odot 2012$ the authors $\quad 0270-6474 / 12 / 327373-11 \$ 15.00 / 0$ navigation (O'Keefe and Dostrovsky, 1971; Squire, 1992), most pyramidal cells encode position by firing in a restricted region of space and are hence called place cells (O'Keefe and Dostrovsky, 1971; Best et al., 2001). Many place cells are modulated by head direction (McNaughton et al., 1983) and a small fraction of pyramidal cells encode head direction independent of position (Leutgeb et al., 2000). Although there are no known hippocampal cells that exclusively encode speed, most hippocampal cells increase their firing rate at higher running speeds (McNaughton et al., 1983). Medial entorhinal cortical grid cells show similar speed-dependent increases in firing rate (Sargolini et al., 2006). Remarkably, although a rat runs through a place/grid field at very different running speeds across trials, the location and size of the place/grid field does not change (Sargolini et al., 2006; Geisler et al., 2007).

In addition to modulation by spatial location, hippocampal neuronal activity is also modulated by a variety of rhythms. The frequencies of these rhythms range from low delta $(0.3-4 \mathrm{~Hz})$ and theta $(6-12 \mathrm{~Hz})$ rhythms to higher frequency beta (15-30 $\mathrm{Hz})$, gamma $(40-80 \mathrm{~Hz})$, high-gamma $(80-120 \mathrm{~Hz})$, and ripple (150-210 Hz) waves (Buzsáki and Draguhn, 2004; Buzsáki, 2006; Singer, 1993; Fries, 2009). Running speed influences both the power and frequency of theta oscillations seen in the hippocampal LFP (McFarland et al., 1975; Slawińska and Kasicki, 1998; Shin and Talnov, 2001; Buzsáki, 2005; Geisler et al., 2007). Gamma oscillations are also prominent in the hippocampus (Bragin et al., 1995; Csicsvari et al., 2003; Montgomery and Buzsáki, 2007; Montgomery et al., 2008). Hippocampal gamma power is elevated at choice-points on a maze and is thus 
thought to be associated with decision-making (Montgomery and Buzsáki, 2007). However, no changes in gamma power (Montgomery and Buzsáki, 2007) or theta-gamma coupling (Tort et al., 2009) have been reported as a function of increasing running speed in rats, whereas gamma power increases with speed in mice (Chen et al., 2011).

Here, we examine how the frequency of hippocampal gamma oscillations changes as a function of the running speed of a rat. We find systematic shifts to higher gamma frequencies at faster running speeds, with important implications for spatial learning and memory. These results were first published online as part of a doctoral dissertation (Ahmed, 2010).

\section{Materials and Methods}

Experimental methods

Subjects. Five male Long-Evans rats aged 4-6 months were housed in individual cages and kept on a reverse, $12 \mathrm{~h}$ day/night cycle. Recordings were performed during the dark phase. For at least 3 weeks before surgery, the animals were handled daily, trained to run on a Y-shaped track, and placed on a restricted diet to maintain their weight at $90 \%$ of their ad libitum-feeding body weight. All animal care and surgical procedures were performed according to the National Institutes of Health guidelines and were approved by the Brown University Institutional Animal Care and Use Committee.

Surgery and electrode implantation. The rats were anesthetized with $1-2 \%$ isoflurane for the duration of the surgeries and chronically implanted with either single- or dual-cannula microdrives. No other anesthetics were administered. Each cannula of the custom-made microdrives contained 4-11 tetrodes. The tetrodes were constructed from 13- $\mu$ m-thick, Teflon-coated, nichrome wire (Kanthal Precision Technology) twisted into four strands. The tip of each electrode strand was gold-plated to reduce the impedance to $100-300 \mathrm{k} \Omega$ tested at $1 \mathrm{kHz}$.

The microdrive cannulae targeting the CA1 region of the hippocampus were located 3.5-5.2 mm posterior to bregma and $2.75-4.15 \mathrm{~mm}$ lateral to the midline, and shaped to follow the long axis of the hippocampus. The drives were secured to the skull using jeweler's screws and dental cement. The cannula(e) of each drive, as well as an additional jeweler's screw above the cerebellum, were all shorted together to act as the electrical ground and all spikes and local field potentials (LFP) were measured with respect to it.

Data collection. Data collection began after allowing a recovery time of 1 week after surgery. All recordings were performed in a sound and electromagnetically shielded room with very dim DC lighting. There were no other sources of sound or light in the room during the data collection. The rats ran on a Y-shaped track, with a long central arm (2.5 $\mathrm{m})$ and shorter left and right arms $(0.5 \mathrm{~m})$. The rats had to alternate between any of the three arms of the track to receive a sugar water reward. Each session lasted between 30 and $60 \mathrm{~min}$. Three of these rats also ran on a two-dimensional platform $(2 \mathrm{D} ; 2 \times 1 \mathrm{~m})$ and were rewarded with small food pellets. Recordings were performed using the Neuralynx Digital Lynx system. The position of red and green LEDs on the rat's head was sampled at $40 \mathrm{~Hz}$ by the Neuralynx video tracker software. Spikes crossing a threshold of $30-50 \mu \mathrm{V}$ on any one of the four tetrode wires were sampled at $32 \mathrm{kHz}$ and bandpass filtered between 600 and $9000 \mathrm{~Hz}$. Well-isolated single units were manually clustered offline using the MClust spike-sorting toolbox for Matlab (A. David Redish, University of Minnesota, Minneapolis, MN). Of 258 well isolated cells, 19 were found to be fast spiking (FS) interneurons and were used for this study. FS interneurons were distinguished from pyramidal cells based on the narrower peak-to-trough widths and larger peak-to-trough amplitudes of FS interneurons (Fox and Ranck, 1981; Cardin et al., 2009). Multiunit activity was defined as all spikes that exceeded threshold.

The LFP was sampled at $4 \mathrm{kHz}$ and bandpass filtered between 0.1 and $900 \mathrm{~Hz}$. The results presented here are derived from a total of $98 \mathrm{LFPs}$ (74 on the Y-shaped track, 24 on the two-dimensional platform) from a total of 39 sessions, each lasting 30-60 min.

\section{Data analysis}

All data were analyzed offline using Matlab (MathWorks).

Speed calculation. The center of mass of the coordinates of the red and green LEDs on the rat's head were computed offline. This represented the $x$ and $y$ position of the rat at each point in time. This position data was low pass filtered to remove noise (Geisler et al., 2007). The speed vector was then calculated based on the displacement between each time point, consistent with previous studies (Geisler et al., 2007).

Binning of speed and spectral data. Each 30-60 min session was binned into sequential $200 \mathrm{~ms}$ time windows with no overlap. The average speed over this time window was calculated by averaging the speed within the $200 \mathrm{~ms}$ period. The power spectrum was calculated for each $200 \mathrm{~ms}$ period as discussed below.

LFP frequency-domain analysis. The Chronux toolbox for Matlab was used to perform multitaper spectral analysis of the LFP. The absolute power spectrum of the LFP during each $200 \mathrm{~ms}$ time window was calculated (in units of $\mu \mathrm{V}^{2} / \mathrm{Hz}$ ). The Chronux toolbox requires two parameters: the time-bandwidth product (TW) and the number of tapers (K), with the number of tapers often set to $2 \mathrm{TW}-1$, with the combination of these parameters helping to determine the amount of smoothing across frequencies. The settings TW $=3$ and $\mathrm{K}=5$ were used (Jarvis and Mitra, 2001). All results presented here were tested using a range of values for these parameters, with no change in the findings.

To compute the averaged absolute power spectra at a given speed, all time windows with that particular average speed were used. The absolute power at each frequency was then averaged across all these time windows (Jarvis and Mitra, 2001). The relative power spectrum has also been used to compare power within a given frequency band across different times and conditions (Cardin et al., 2009). Hence, we analyzed the relationship of both relative and absolute power with speed. Relative power was calculated as the fraction of total power at each frequency in each time window (Cardin et al., 2009). In all color-coded plots, such as Figure $1 A$, the relative or absolute power at each frequency was $z$-scored separately across all data within each speed bin to make visual comparisons across different frequencies easier and to compensate for the typical $1 / f$ decay of LFP power.

The coherence between a pair of simultaneously recorded LFPs was also calculated using the Chronux toolbox (Gregoriou et al., 2009), using $\mathrm{TW}=3$ and $\mathrm{K}=5$. Coherence values for each frequency range from 0 to 1 , with 1 representing maximal coherence. To analyze the change in coherence as a function of speed, electrode pairs located directly along the long axis of the hippocampus of a single hemisphere were used. No comparisons of electrodes in different hemispheres were made.

\section{Results \\ Frequency of gamma oscillations increases at faster running speeds}

To encourage the rats to run at a variety of speeds, we constructed a Y-shaped track with a 2.5-m-long central arm and shorter $0.5 \mathrm{~m}$ left and right arms. Rats were free to alternate between any pair of arms, and they generally reached speeds of up to $100 \mathrm{~cm} / \mathrm{s}$ on the long arm (Fig. 1A). As the rats ran, we used tetrodes to record both the LFP and spiking activity from the CA1 region of the hippocampus (see Materials and Methods). We first computed the $Z$-scored relative power spectrogram together with the speed of the rat over an $80 \mathrm{~s}$ period (Fig. $1 \mathrm{~A}$ ). As the rat ran faster, the power at lower frequencies appeared to decrease, whereas the power at higher frequencies appeared to increase (Fig. 1A,B).

To quantify these changes, we computed the rat's speed and the LFP-spectral power in consecutive $200 \mathrm{~ms}$ bins (see Materials and Methods). The time period of $200 \mathrm{~ms}$ was chosen because it was short enough to exclude any significant changes in the rat's running speed, and long enough to calculate the power spectrum of the LFP for gamma frequencies. The distribution of average speeds confirmed that the rat spent more time at lower speeds, but often maintained average speeds well above $60 \mathrm{~cm} / \mathrm{s}$ over the $200 \mathrm{~ms}$ time windows (Fig. $2 A$ ). The absolute power spectra as a 
A

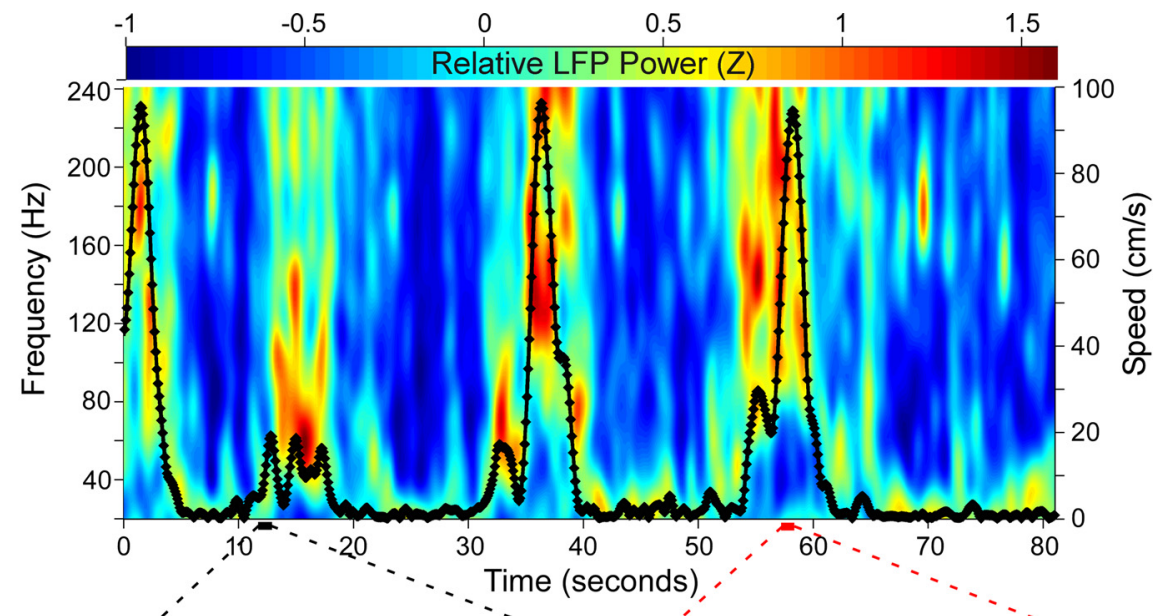

B

Raw LFP

Filtered .
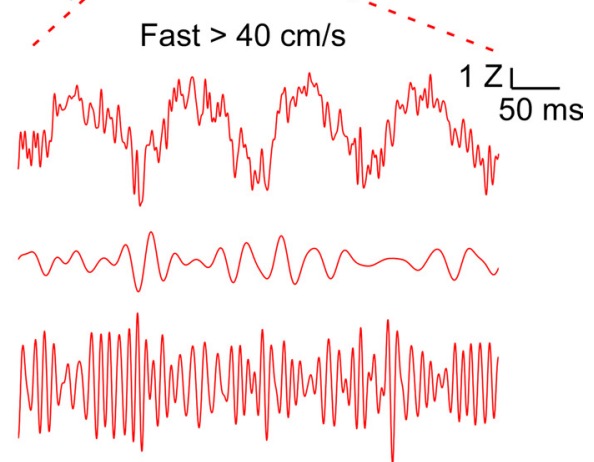

Figure 1. Examples of the frequency changes seen in the hippocampal LFP as a function of running speed. $A$, Spectrogram showing the changes in frequency as the rat ran freely on a Y-shaped track. The rat's running speed is overlaid in black. Note the increased high-frequency power accompanying increases in the rat's running speed. $\boldsymbol{B}$, Two 500 ms segments showing the LFP activity at slow (left, black traces) and fast (right, red traces) running speeds. The raw, unfiltered LFP shows slower oscillations at the slow speed, and faster oscillations at fast running speeds. Filtering the data in the low gamma $(25-50 \mathrm{~Hz})$ and high gamma $(65-140 \mathrm{~Hz})$ range reveal clear differences in the amplitudes of the signals. Low gamma power is higher at slow speeds and high gamma power is higher at fast speeds. Low and high gamma frequency ranges were defined in accordance with the results of Colgin et al. (2009).

function of running speeds were then calculated (Figs. $2 B-D$ ). We first compared the absolute power spectra during immobility $(0-2 \mathrm{~cm} / \mathrm{s})$ and high-speed runs $(60-120 \mathrm{~cm} / \mathrm{s} ;$ Fig. $2 C)$. For each frequency, we calculated the ratio of absolute power during the two conditions. Low-frequency $(30-60 \mathrm{~Hz})$ power was significantly higher during immobility than at fast speeds $(p<0.001)$. However, power at higher frequencies $(70-240$ $\mathrm{Hz}$ ) was significantly higher while running at fast speeds $(p<$ 0.001 ). The LFP absolute power ratios showed a clear trend, increasing systematically from low to high frequencies (Fig. $2 C$, bottom). The only deviation from this linear trend appeared $\sim 180 \mathrm{~Hz}$ (Figs. 1A, 2C), which is the frequency of sharp-wave associated ripples that occur preferentially during immobility (Buzsáki et al., 1992).

Did these frequency shifts represent discrete differences between immobile and run states, or were there gradual changes in frequency as a function of speed? To address this question, we compared the absolute power spectra at two closely matched running speeds, $10-30 \mathrm{~cm} / \mathrm{s}$ versus $30-50 \mathrm{~cm} / \mathrm{s}$ (Fig. $2 D$ ). Once again, we saw the same pattern: low frequencies $(30-65 \mathrm{~Hz})$ had more power at slower speeds, and high frequencies $(90-240 \mathrm{~Hz})$ had more power at faster speeds ( $p<0.001$ in all cases). Thus it appeared that there was a gradual shift in power to higher frequencies at higher speeds. To confirm this, we overlaid the absolute power spectra at 50 different speeds, and saw the same trend (Fig. $2 \mathrm{~B}$ ): clear, systematic changes in the slope of the absolute power spectra, reflecting the shift in power from low to high frequencies as a function of increasing speed.
The use of color-coded plots to represent the $Z$-scored relative power at each frequency and at each speed clearly demonstrated the systematic increases in frequency as a function of increasing speeds (Fig. 2E). These changes spanned the entire range of frequencies traditionally associated with low and high gamma oscillations $(30-120 \mathrm{~Hz})$. For this session, the absolute power at low frequencies $(30-52 \mathrm{~Hz})$ was significantly negatively correlated with running speed ( $p<0.001$; Fig. $2 F$, black bars), and the absolute power at high frequencies $(65-240 \mathrm{~Hz})$ was significantly positively correlated with running speed $(p<0.001$; Fig. $2 F$, red bars). The correlations were most negative at $34 \mathrm{~Hz}$ and most positive at $120 \mathrm{~Hz}$, corresponding to the broadest definition of gamma frequencies. An important consequence of these systematic changes in frequency was that the absolute power of frequencies between 52 and $65 \mathrm{~Hz}$ was uncorrelated with speed (Fig. 2F, green bars). This is because the power at these frequencies increased from 0 to $10 \mathrm{~cm} / \mathrm{s}$, and then decreased at higher speeds (Fig. 2E). Thus, running speed appears to modulate the frequency of gamma oscillations, leading to differential amplitude modulation of each individual frequency (Fig. 2E,F). Similar increases in gamma frequency as a function of speed were clearly evident in individual LFPs from four unique rats (Fig. 3), and the population-averaged results ( $N=74$ LFPs, 5 rats) very closely resembled those described for the representative examples (see Fig. 5A,C,E). Both absolute power and relative power showed very similar relationships with running speed (see Fig. 5, compare $A, C)$. Thus, the frequency of hippocampal CA1 gamma oscillations is modulated by the running speed of the rat. 

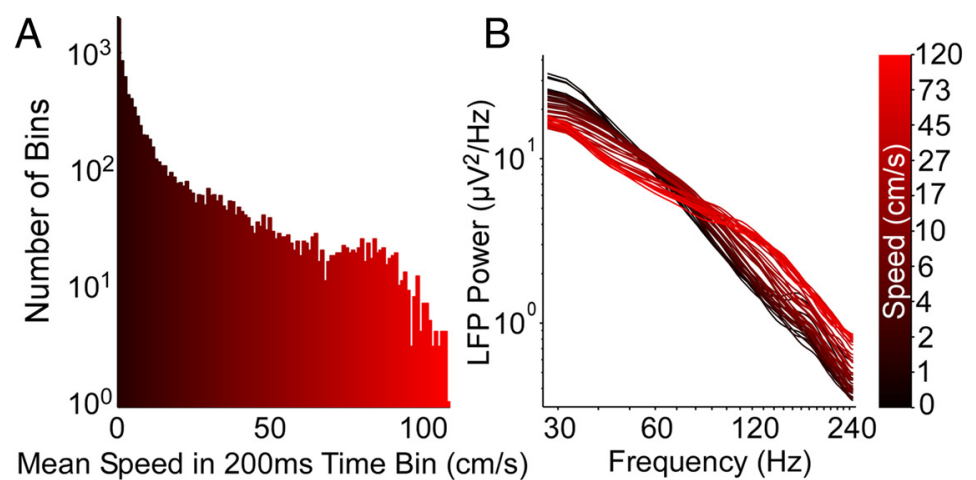

Mean Speed in $200 \mathrm{~ms}$ Time Bin $(\mathrm{cm} / \mathrm{s})$
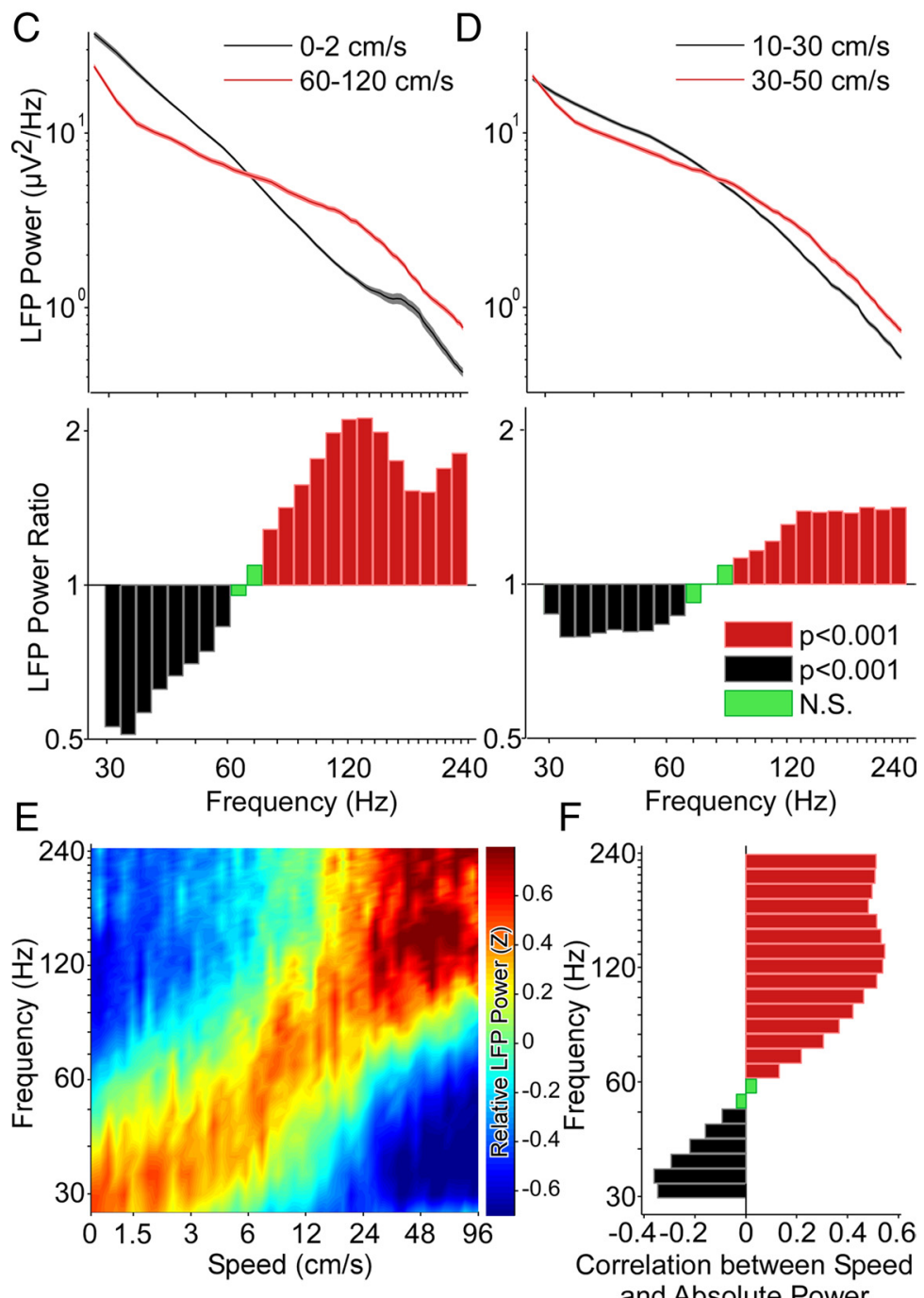

Figure 2. Running speed alters the frequency of hippocampal LFP. A, The 45 min session on the track was divided into $200 \mathrm{~ms}$ segments. This histogram shows the distribution of mean running speeds across all 13384 segments in this session. The power in each frequency band was also calculated in each of these segments and was used to generate $\boldsymbol{B}-\boldsymbol{F}$. $\boldsymbol{B}$, Overlaid spectra calculated at 50 different speeds. The color of a spectrum represents the speed at which the spectrum was calculated: black is slow, red is fast. There is a decrease in slope of the spectra as speed increases, suggesting that the frequency content changes with speed. C, Top, Comparison of the averaged spectra during immobility $(0-2 \mathrm{~cm} / \mathrm{s})$ versus running at fast speeds $(>60 \mathrm{~cm} / \mathrm{s})$. Confidence intervals $(95 \%)$ are plotted around each point, but are too small to be easily visible, indicating extremely low SES. Bottom, Ratio of power in the fast segments to power in the immobile segments. The black bars represent frequencies that had significantly higher power during immobility $(t$ test; $p<0.001$, Bonferroni-adjusted for multiple comparisons), whereas the red bars identify frequencies that had significantly higher power during periods of high speed running. Green bars indicate frequencies that were not significantly different in the two conditions. Low frequencies have more power during immobility than running, whereas high frequencies have more power while running. The two spectra cross at 68 $\mathrm{Hz}$. The dip $\sim 180 \mathrm{~Hz}$ corresponds to the increased power in the $160-200 \mathrm{~Hz}$ frequency band during immobility ripples. $D$, Similar to $C$, but comparing two closely matched running speeds, $10-30 \mathrm{~cm} / \mathrm{s}$ versus $30-50 \mathrm{~cm} / \mathrm{s}$. Confidence intervals $(95 \%)$ are included, but are too small to be visible. Note that significant differences in the frequency structure are seen despite the fact that the rat is running in both
Speed-dependent changes in gamma frequency are independent of spatial behavior

We next asked whether these speeddependent changes in gamma frequency were independent of spatial behavior. We wanted to test the possibility that gamma frequency was correlated with speed only on linear tracks, and not in two-dimensional environments. Hence, we recorded from rats as they randomly foraged a large 2D platform immediately after or before they ran on the linear Y-shaped track. Before surgery, the rats had been pretrained to run on the Y-shaped track, but the 2D maze was a relatively novel environment. The rats were rewarded with sugar water on the Y-shaped track but were given small food pellets on the $2 \mathrm{D}$ platform. Thus, we were able to record the LFP from the same CA1 anatomical location as the rat explored two very different spatial environments and behaviors, and examine the speedfrequency relationship in each case. Figure $4 A-H$ shows one such experiment, where the rat was transferred from a familiar Y-shaped linear track (Fig. 4A) to a novel 2D platform (Fig. $4 B$ ). The rat ran at slower speeds on the 2D platform (Fig. $4 D$ ). However, the rat still maintained average speeds just above $40 \mathrm{~cm} / \mathrm{s}$ over many 200 ms periods. Even on this novel 2D platform, the frequency of oscillations increased as a function of speed (Fig. $4 F$ ). The correlations between absolute power and speed were most negative at $30 \mathrm{~Hz}$ and most positive at $120 \mathrm{~Hz}$ (Fig. $4 \mathrm{H}$ ), consistent with the correlations seen on the Y-shaped track (Fig. 4G). The only difference we noted on the 2D platform was increased power concentrated $\sim 180 \mathrm{~Hz}$ during immobility, suggesting the possible occurrence of more sharpwave associated ripples on the novel $2 \mathrm{D}$ environment. The population-averaged

$\longleftarrow$

conditions, suggesting a quantitative influence of running speed on the frequency structure of the local field potential. $\boldsymbol{E}$, This is confirmed by computing the relative power at each frequency across all speed ranges. The color represents the Z-scored relative power in each frequency band. The power shifts in a graded manner to higher frequencies as a function of increasing speed. $\boldsymbol{F}$, The absolute power at each frequency band was independently correlated with running speed. Significant negative correlations (black, $p<0.001$, Bonferroniadjusted) were seen for lower frequencies. These correlations became progressively less negative with increasing frequency, transitioning to significant positive correlations $>65 \mathrm{~Hz}$. Thus the precise frequency of network gamma oscillations strongly depends on the running speed of the animal, with higher speeds resulting in higher gamma frequencies. 

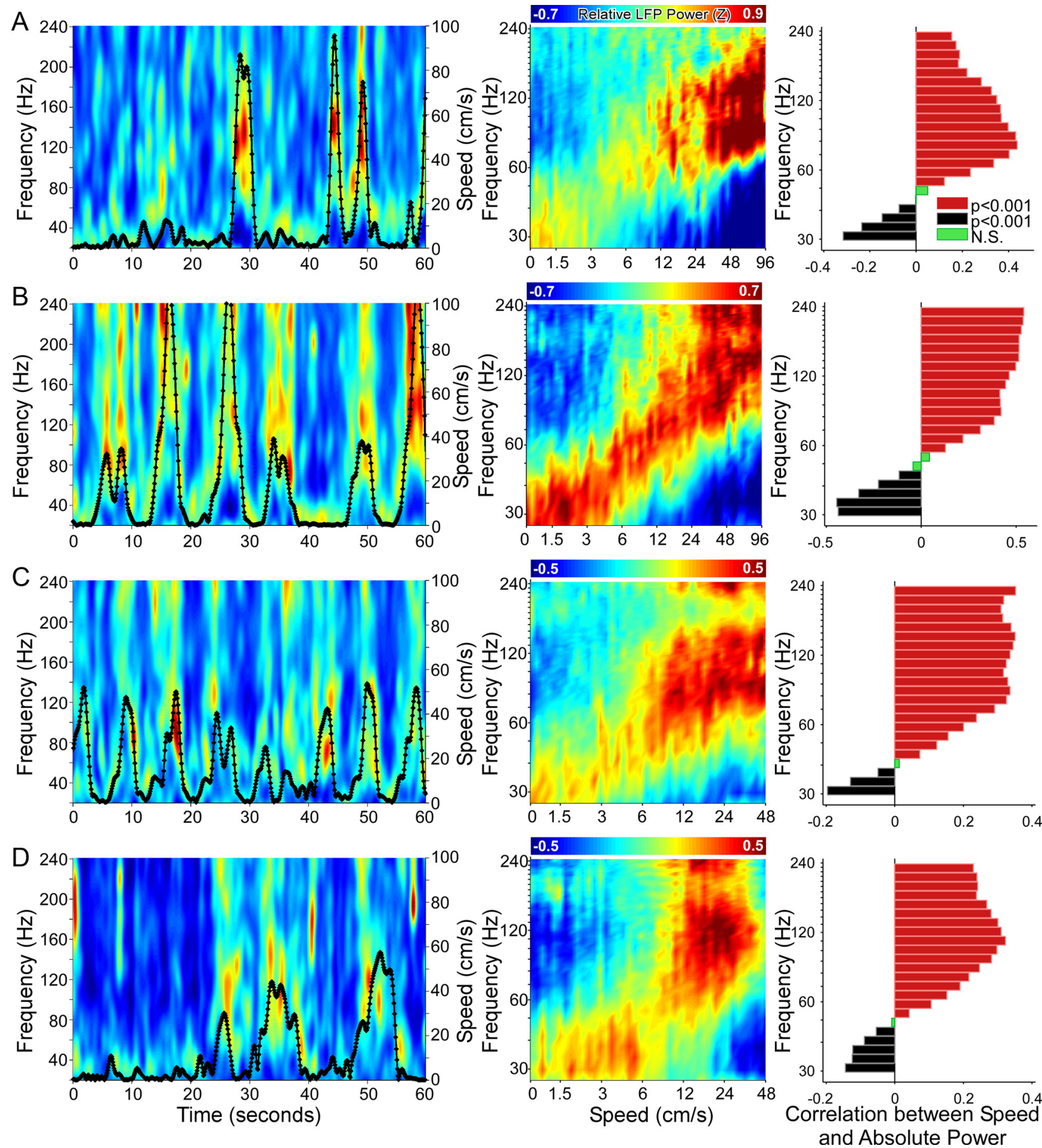

Figure 3. Additional examples showing increases in LFP gamma frequency as a function of increasing speed in four rats. $A$, Left, Spectrogram over a 60 s time period, showing the changes in relative power at each frequency as a rat ran freely on a Y-shaped track for an LFP recorded from the hippocampus. The rat's running speed is overlaid in black. Middle, For the same LFP, the relative power across the session is color coded as a function of both speed and frequency: power shifts to higher frequencies at faster running speeds. Right, For the same LFP, absolute power at lower gamma frequencies is negatively correlated with speed, whereas absolute power at higher gamma frequencies is positively correlated with speed. $\boldsymbol{B}, \boldsymbol{C}, \boldsymbol{D}$, Data from single LFPs recorded from three other rats show similar increases in gamma frequency as a function of speed.

$2 \mathrm{D}$ platform results ( $N=24 \mathrm{LFPs}, 3$ rats) very closely resembled those described for this representative example (Fig. $5 B, D, F$ ). Once again, both absolute and relative power showed similar relationships to running speed. Thus, we conclude that the frequency of hippocampal gamma oscillations is altered at different running speeds, and that these speed-dependent changes are independent of spatial behaviors.
Theta power increases at faster running speeds

To analyze the effect of running speed on frequencies between 6 and $30 \mathrm{~Hz}$, we used $600 \mathrm{~ms}$ time bins to calculate the power spectra. This ensured that there were a sufficient number of theta cycles in each time window to get a good estimate of theta power. Consistent with previous findings (McFarland et al., 1975; Slawińska and Kasicki, 1998; Shin and Talnov, 2001; Buzsáki, 

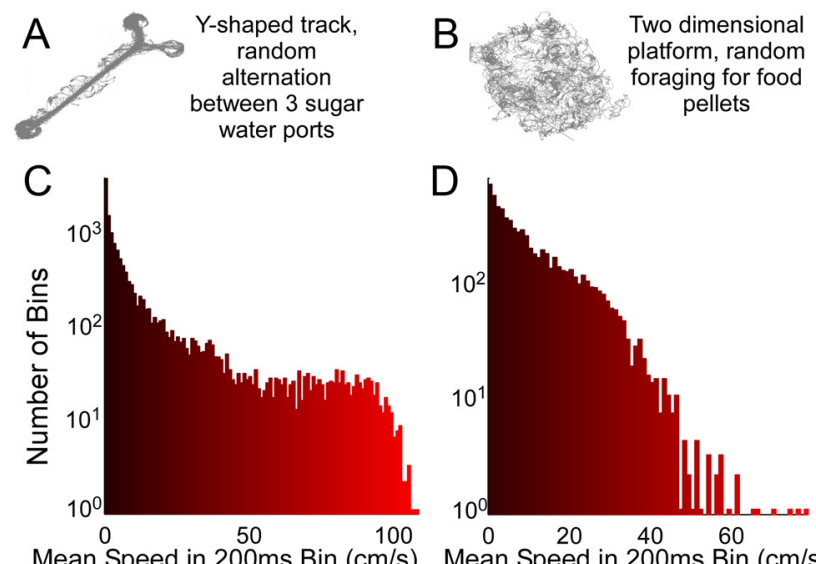

Mean Speed in $200 \mathrm{~ms}$ Bin $(\mathrm{cm} / \mathrm{s})$
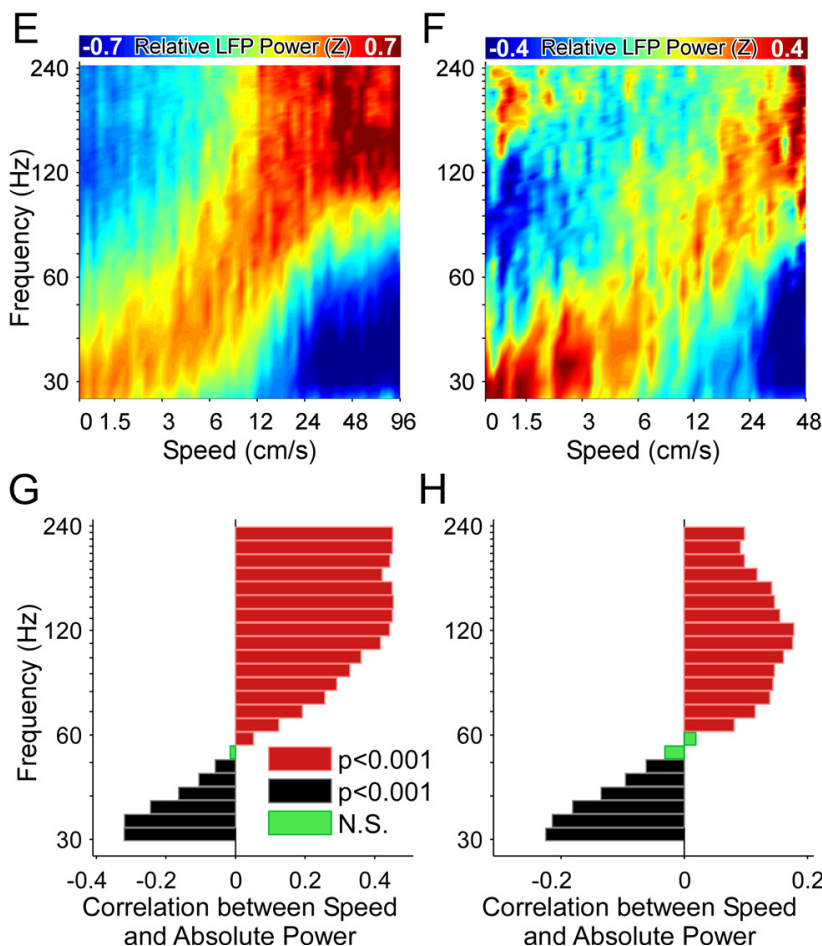

$\mathrm{H}$

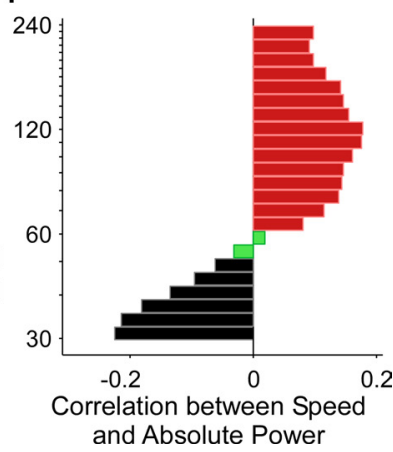

Figure 4. Running speed modulation of LFP frequency is independent of spatial environment. $A, C, E$, Speed modulation of the oscillation frequency of a single hippocampal LFP on a Y-shaped track. $B, D, F$, LFP recorded at the same tetrode location as the rat ran on a twodimensional platform immediately after the track session. Similar modulation of frequency by running speed is seen in both environments. $\boldsymbol{A}, \boldsymbol{B}$, The spatial occupancy maps in each of the two conditions showing the very different shapes of the two environments. $C, D$, The distribution of speeds measured $>200 \mathrm{~ms}$ bins in the two environments. $\boldsymbol{E}-\boldsymbol{H}$, The power shifts in a graded manner to higher frequencies as a function of increasing running speed in both spatial conditions.

2005; Geisler et al., 2007), we found that power at all frequencies within the theta range $(6-12 \mathrm{~Hz})$ was positively correlated with running speed (Fig. $6 A, B$ ). There was a very different relationship above $12 \mathrm{~Hz}$, with frequencies between 18 and $30 \mathrm{~Hz}$ being significantly negatively correlated with running speed (Fig. $6 A, B)$.

Gamma-band coherence shifts to higher frequencies at faster running speeds

We reasoned that for the speed-dependent increase in gamma frequency to be a meaningful reflection of synchrony at higher frequencies, the coherence (Sabolek et al., 2009) between ana-
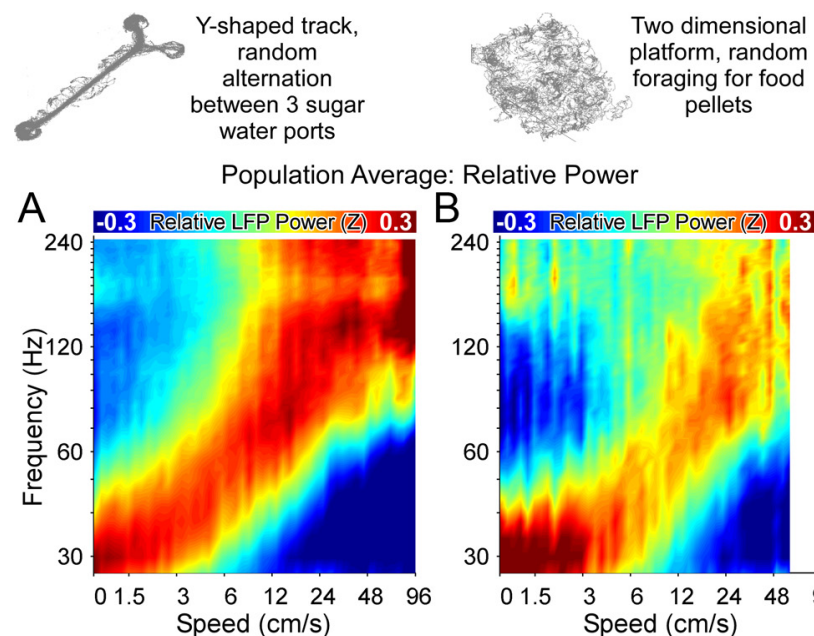

Population Average: Absolute Power
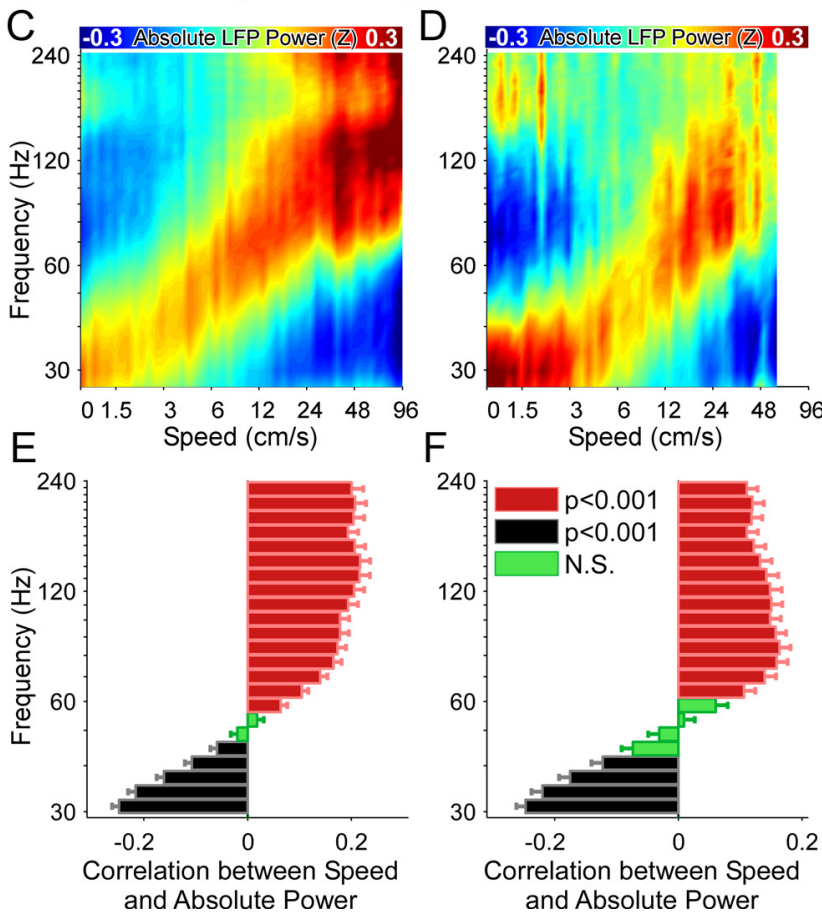

$\mathrm{F}$
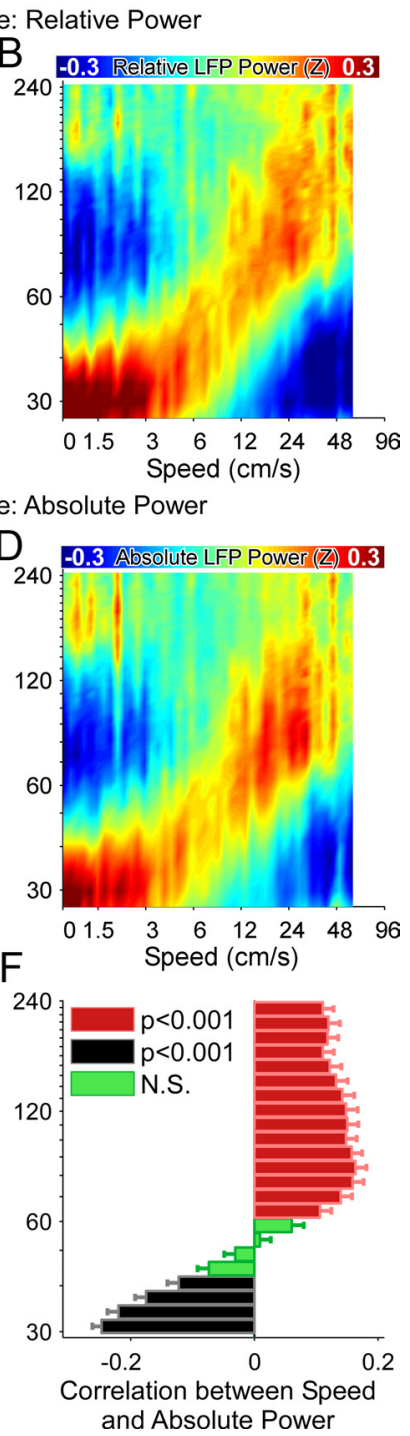

Figure 5. Population averages show that running speed changes the frequency of $C A 1$ gamma oscillations on both linear and two-dimensional tracks. $\boldsymbol{A}, \boldsymbol{C}, \boldsymbol{E}$, Population data from 74 LFPs recorded on Y-shaped tracks. $\boldsymbol{B}, \boldsymbol{D}, \boldsymbol{F}$, Population data from 24 LFPs recorded on twodimensional platforms. $\boldsymbol{A}, \boldsymbol{B}$, Color-coded population averages of relative power as a function of speed. $\boldsymbol{C}, \boldsymbol{D}$, Color-coded population averages of absolute power as a function of speed. Note the very similar relationships obtained using both relative and absolute measures of power. $\boldsymbol{E}, \boldsymbol{F}$, Low frequencies are negatively correlated, and high frequencies are positively correlated with running speed in each environment. All correlations are performed using absolute power measures. Thus the progressive frequency shift across the gamma-range is independent of the spatial environment.

tomically disparate CA1 regions should also shift to higher frequencies in a speed-dependent manner. This would also control against the possibility of single electrode spike bleed-over. Thus we compared the coherence between a pair of simultaneously recorded CA1 LFPs separated by $\sim 700 \mu \mathrm{m}$ along the long axis of the hippocampus at different running speeds (Fig. $7 A, B$ ). The coherence showed shifts to higher frequencies at faster running speeds. We quantified these shifts in two ways. First we plotted the gamma frequency that showed the maximal coherence at each running speed. For this same pair of LFPs, the most coherent 

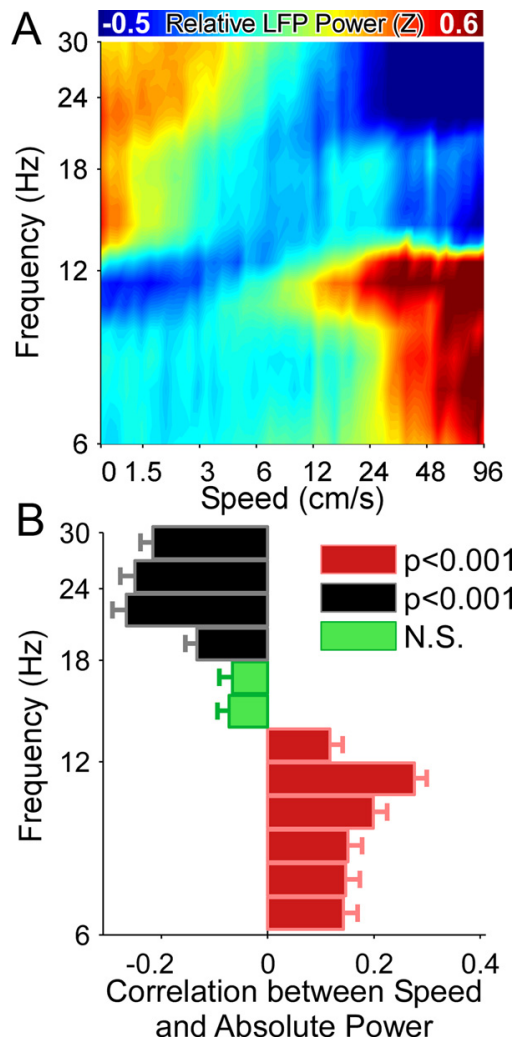

Figure 6. Increased running speed correlates with increased theta power. $A$, Population data from 74 LFPs recorded on Y-shaped tracks showing the effect of running speed on LFP frequencies between 6 and $30 \mathrm{~Hz}$. Theta power $(6-12 \mathrm{~Hz})$ increases at faster running speeds, whereas power at $13-30 \mathrm{~Hz}$ decreases. $\boldsymbol{B}$, Theta frequencies $(6-12 \mathrm{~Hz})$ are significantly positively correlated with running speed, whereas frequencies between 18 and $30 \mathrm{~Hz}$ are significantly negatively correlated with speed.

frequency shifted from $30 \mathrm{~Hz}$ at the slowest speeds to $90 \mathrm{~Hz}$ at the highest speeds. There was a strong correlation between running speed bins and the average maximally coherent frequency for that speed bin $(r=0.95, p<0.001$; Fig. $7 C)$. Second, as with absolute power, we calculated the correlation between the coherence at each frequency and speed. As seen with absolute power, coherence at lower gamma frequencies was negatively correlated with speed, and coherence at higher gamma frequencies was positively correlated with speed (Fig. 7D). For the same session, we also recorded a third hippocampal LFP. This allowed us to analyze a pair of electrodes that were separated by $\sim 300 \mu \mathrm{m}$. Consistent with previous observations (Sabolek et al., 2009), the coherences were slightly higher at this smaller separation distance (Fig. 7E) than at the larger interelectrode distance (Fig. 7A). Importantly, however, identical correlations were seen between LFP-LFP coherence at each frequency and running speed (Fig. 7, compare $D, F)$. We also simultaneously recorded the LFP from a neocortical electrode $\sim 600 \mu \mathrm{m}$ away from one of the hippocampal electrodes. The coherences at all frequencies in this pair were lower $(<0.3)$ than those observed between similarly spaced hippocampal electrodes, and there was no correlation between the most coherent frequency and running speed $(p=0.63$; data not shown). This suggests that the coherence observed within the hippocampus is not due to a common reference or ground, as all electrodes were referenced to the same ground. Volume conductance in the brain has been shown to be isotropic, dropping off equally in all directions (Kajikawa and Schroeder, 2011). Thus, if volume conductance was the sole reason for seeing within-
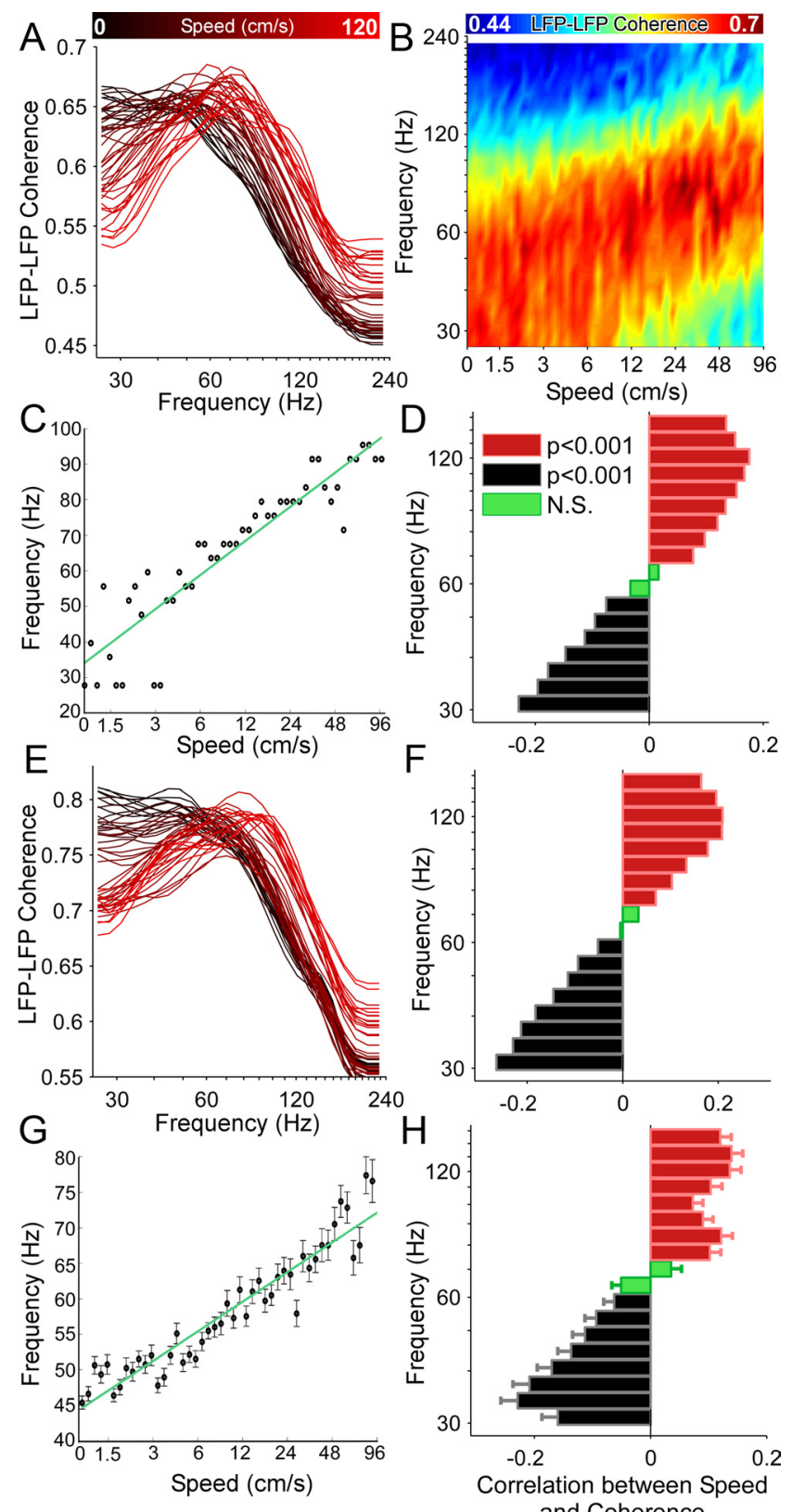

and Coherence

Figure 7. Increased running speed is accompanied by LFP-LFP coherence at higher gamma frequencies. $A$, Coherence between two hippocampal electrodes provides a measure of the synchrony across the long axis of the hippocampus. Here the coherence between two electrodes in CA1, positioned $0.7 \mathrm{~mm}$ apart, is shown at different speeds. Black indicates slow speeds, red indicates faster speeds. The coherence curves shift to higher gamma frequencies as a function of speed. $\boldsymbol{B}$, The same data as in $\boldsymbol{A}$, with color-coded coherence. The shift to higher frequencies in the gamma range $(30-120 \mathrm{~Hz})$ as a function of increasing speed is clearly visible. $C$, The running speed of the rat is plotted against the maximally coherent frequency at each speed. These data are from the same LFPs shown in $\boldsymbol{A}$ and $\boldsymbol{B}$. The most-coherent frequency robustly increases as a function of running speed $(r=0.95, p<0.001)$, showing that the frequency of network oscillations shifts to higher frequencies synchronously across the hippocampus at faster speeds. $D$, The LFP-LFP coherence (same data as $\boldsymbol{A}-\boldsymbol{C}$ ) at each frequency band was independently correlated with running speed. Significant negative correlations (black, $p<0.001$, Bonferroniadjusted) were seen for lower frequencies. These correlations became progressively less negative with increasing frequency, transitioning to significant positive correlations $\sim 70 \mathrm{~Hz}$ (red, $p<0.001$ ). Thus coherence and power show very similar relationships to running speed. $\boldsymbol{E}$, Another example from the same session showing an electrode pair separated by $0.3 \mathrm{~mm}$. Note the higher coherences in this case, but identical shifts to higher frequencies at higher speeds. Color coded as described in $\boldsymbol{A}$. $\boldsymbol{F}$, Correlations for the pair shown in $\boldsymbol{E}$. Color coded as described in $\boldsymbol{D}$. $\boldsymbol{G}$, Same as $\boldsymbol{C}$, but for the entire population data. $\boldsymbol{H}$, Same as $\boldsymbol{D}$ and $\boldsymbol{F}$, but for the entire population data. 
hippocampus LFP-LFP coherence change as a function of running speed, the same relationship would be expected between a similarly spaced neocortex-hippocampal LFP pair. However, since this was not observed, we can also rule out volume conduction as an explanation for our results. The full impact of volume conductance on LFP signals continues to be an important research topic (Kajikawa and Schroeder, 2011). Similar results were seen for the population data: there was a strong correlation between maximally coherent frequency and speed for the population-averaged data $[r=0.97, p<0.001 ; N=34$ LFP-LFP pairs, 4 rats (one of the rats did not have at least two electrodes in the same hippocampal hemisphere at the same time and hence could not be used for coherence calculations); Fig. $7 G$ ], with the average maximally coherent frequency shifting from $45 \mathrm{~Hz}$ at the slowest speeds to $75 \mathrm{~Hz}$ at the highest speeds. Similarly, the population averaged correlation between LFP-LFP coherence at each frequency showed the same trend as the two examples (Fig. $7 \mathrm{H}$ ). Thus, the synchrony between anatomically distinct CA1 populations systematically shifts to higher gamma frequencies as running speed increases.

\section{Interneuron and pyramidal neuron firing rates correlate with} changes in gamma frequency

How could an increase in running speed lead to an increase in gamma frequency? Traub et al. (1996) have proposed that one factor controlling the frequency of gamma oscillations is the amount of excitatory drive to a network of interneurons. Their models and in vitro experiments suggest that the stronger the excitatory drive to an interneuron, the higher the frequency of gamma oscillations. We hypothesized that a similar mechanism may explain our observations. Running speed has been shown to increase the firing rate of both CA3 place cells (Diba and Buzsáki, 2008) and medial entorhinal cortex (EC) layer III grid, headdirection, and conjunctive cells (Sargolini et al., 2006). Since these two regions are thought to provide the majority of feedforward excitatory inputs to CA1 (Witter and Amaral, 2004; Ahmed and Mehta, 2009), the net excitatory drive to CA1 pyramidal cells and interneurons is expected to increase as a function of speed. Indeed, we found that the firing rates of two simultaneously recorded CA1 interneurons increased as a function of speed (Fig. $8 A, B$ ), consistent with previously reported observations (Czurkó et al., 1999; Nitz and McNaughton, 2004). The two interneurons had very different mean rates, 33 and $69 \mathrm{~Hz}$, respectively. However, the $Z$-scored firing rate, and not the absolute rate, of each interneuron was predictive of the frequency of LFP oscillations recorded simultaneously on another (non-local) CA1 electrode (Fig. $8 C-F$ ). Similar results were seen in the population averages for all interneurons (Fig. 9A,B). Consistent with increased feedforward drive of both pyramidal cells and interneurons, similar results were seen for multiple-single-unit activity (where we combined the activity of two or more pyramidal neurons recorded simultaneously, thus helping to overcome their sparse firing profiles; Fig. $9 C, D$ ) and for multiunit-activity (MUA: all multiunit activity exceeding spike threshold, including all spikes generated by pyramidal neurons as well as interneurons; Fig. $9 E, F)$. Thus, changes in the firing rate of an individual interneuron, or an ensemble of pyramidal neurons, relative to its mean firing rate can be used to predict the frequency of hippocampal network gamma oscillations, even on distant CA1 electrodes. These results could be a consequence of either interneuronalnetwork-gamma (ING) or pyramidal-interneuronal network gamma (PING), with PING being more likely given the similar speed-dependent increases in both interneuron and pyramidal
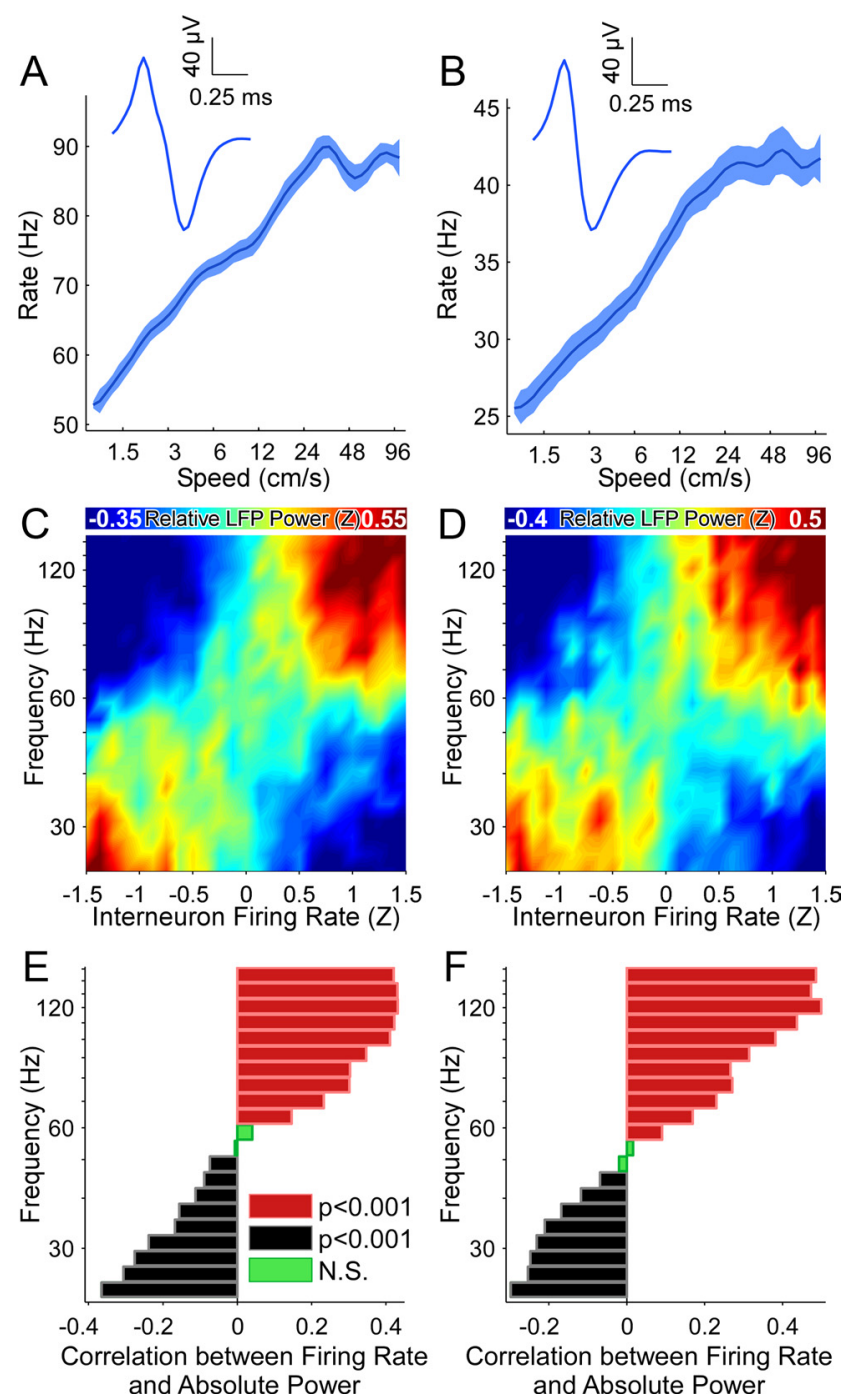

Figure 8. Firing rates of individual interneurons correlate with the gamma frequency of hippocampal LFP. Data from two interneurons, recorded simultaneously on the same tetrode as the rat ran on a $y$-shaped track. $A, C, E$, Interneuron 1 , which had a mean firing rate of $33 \mathrm{~Hz} . B, D, F$, Interneuron 2 , which had a mean firing rate of $69 \mathrm{~Hz}$. $A, B$, Both interneurons increase their firing rate as a function of increasing speed. Insets, The narrow extracellular spike shapes are indicative of putative fast-spiking interneurons. C, D, As the normalized (Z-scored) rate of each interneuron increases, there is a shift to higher LFP frequencies. The interneuron and LFP were recorded simultaneously on different hippocampal electrodes. Note that this shift is independent of the absolute firing rates of the two interneurons, and instead depends on the firing rate of each interneuron relative to its mean rate. $\boldsymbol{E}, \boldsymbol{F}$, Lower LFP frequencies are negatively correlated with each interneuron's Z-scored firing rate, whereas higher frequencies are positively correlated. Thus the normalized rate of interneuron firing is predictive of the shift in LFP frequencies across the gamma-band.

neuron firing rates within CA1 (Börgers et al., 2005; Tiesinga and Sejnowski, 2009). However, while our results show consistent correlations between interneuron firing rate and gamma frequency, they do not prove a causal relationship between the two. Careful hippocampal optogenetic experiments can help to test the causality of this relationship in vivo in the future.

\section{Discussion}

We have shown that the frequency of hippocampal gamma oscillations increases as the running speed of a rat increases (Figs. $1-3)$. This is true on familiar, linear tracks as well as in novel, two-dimensional environments (Figs. 4, 5). The coherence between distant CA1 regions also shifts to higher gamma frequen- 
Interneurons
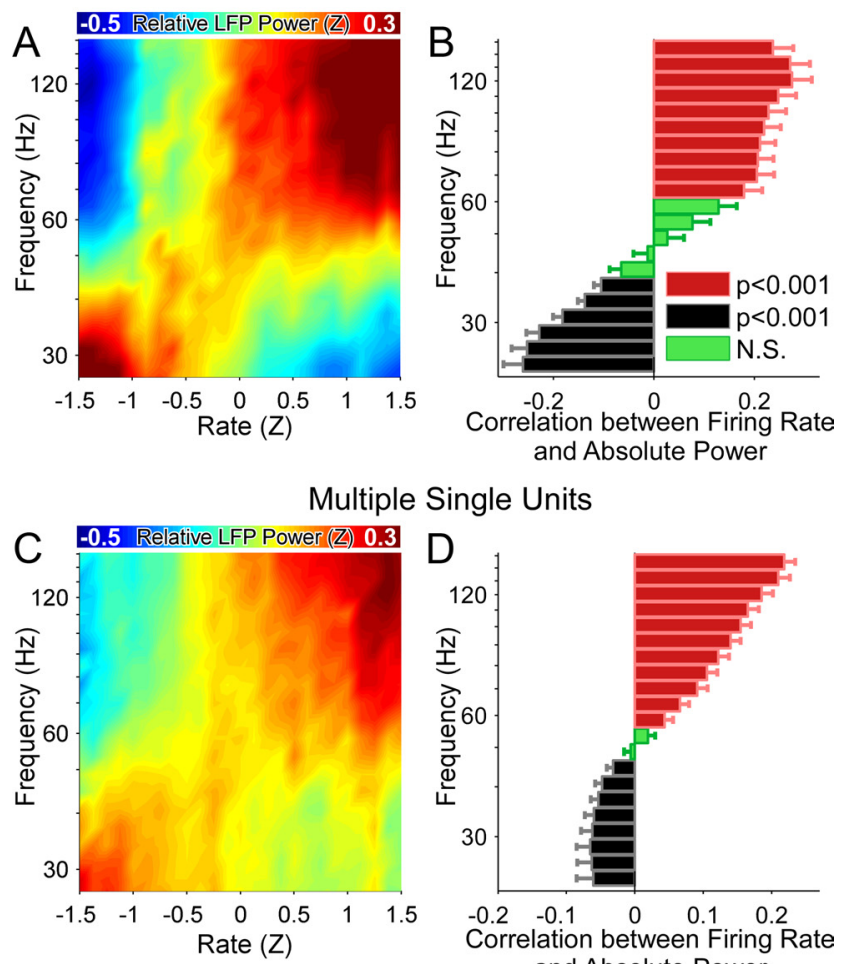

and Absolute Power

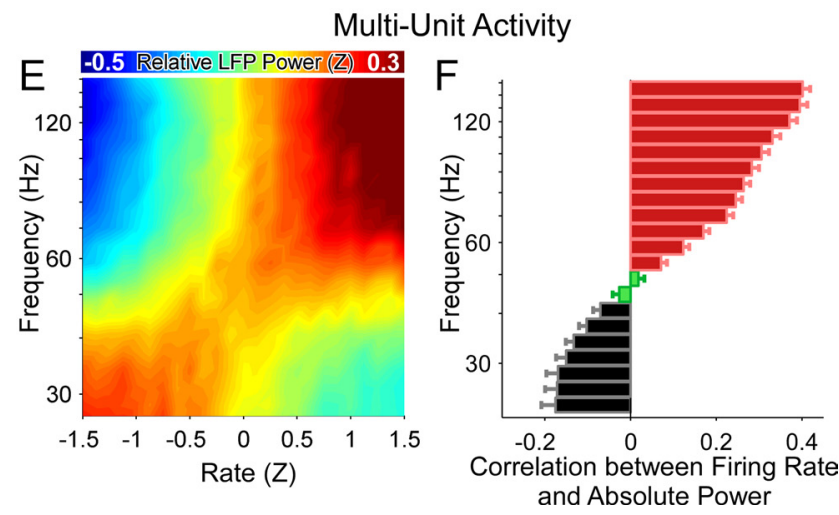

Figure 9. Firing rates of individual interneurons and multiunit activity correlate with the frequency of hippocampal LFP_-population averages. $\boldsymbol{A}$, As the mean Z-scored firing rate of the population of interneurons increases, the frequency of CA1 gamma oscillations also increases. $\boldsymbol{B}$, Lower gamma frequencies are more likely at lower interneuron firing rates, whereas higher gamma frequencies are more likely at higher interneuron firing rates. $\boldsymbol{C}, \boldsymbol{D}$, Similar to $\boldsymbol{A}$ and $\boldsymbol{B}$, but for multiple single unit activity of pyramidal cells. $\boldsymbol{E}, \boldsymbol{F}$, Similar to $\boldsymbol{A}$ and $\boldsymbol{B}$, but for all multiunit activity.

cies as the rat runs faster (Fig. 7). As predicted by previous models and in vitro experiments (Traub et al., 1996), the firing rate of interneurons is strongly correlated with the frequency of hippocampal gamma oscillations (Figs. 8, 9). We now discuss the implications of these results in the context of recent work on hippocampal and entorhinal gamma oscillations.

\section{Differential contributions of CA3 and EC inputs at different speeds?}

CA1 pyramidal cells receive inputs from both CA3 and EC (Witter and Amaral, 2004). CA3 inputs are localized to the basal and proximal apical dendrites of CA1 pyramidal cells, whereas inputs from the EC are restricted to the most distal apical dendrites. Which of these two inputs is responsible for the spatially precise output of CA1 place cells (Ahmed and Mehta, 2009)? The analysis of gamma oscillations may shed some light on this question. Recent work has shown that higher frequency $(65-140 \mathrm{~Hz}) \mathrm{CA} 1$ gamma oscillations in rats are more coherent with high-frequency gamma oscillations in the EC, whereas lower frequency $(25-50 \mathrm{~Hz}) \mathrm{CA} 1$ gamma oscillations are more coherent with lowfrequency gamma oscillations in CA3 (Colgin et al., 2009). Our results show that high-frequency gamma oscillations in CA1 are more likely at faster running speeds, whereas low-frequency CA1 gamma oscillations are more likely during immobility and slow running speeds (Figs. 1-6). Colgin et al. (2009) also noted a somewhat reduced speed during their low-frequency gamma events compared with high-frequency events in CA1, consistent with our findings. The combination of these results suggests the hypothesis that CA1 might be preferentially driven by the entorhinal cortex at faster running speeds and by CA3 at slower running speeds. This prediction can be experimentally tested in the future by recording simultaneously from the medial EC (MEC), $\mathrm{CA} 3$, and CA1, and calculating the coherence between the regions as rats run at different running speeds.

\section{Comparison to previous studies: gamma power versus gamma frequency}

Our results are complementary to recent findings (Montgomery and Buzsáki, 2007) of no correlations between gamma power and running speed. Montgomery and Buzsáki (2007) calculated a single value for power spanning the entire gamma range (defined by them as $40-120 \mathrm{~Hz}$ ). This gives the total power over all frequencies in this range. They then correlated this total gamma power to the running speed of the rat, and reported no significant correlations between the two variables using a generalized linear model. As we have shown here, power shifts from low frequencies to high frequencies at increased running speeds. Thus the total power over the entire gamma range does not change significantly. When we correlated the total power between 40 and $120 \mathrm{~Hz}$ with the running speed of a rat in our data, we too found no correlation $(r=0.003, p=0.96$, N.S. $)$.

Our results differ from what has recently been reported in mice. Both low and high gamma power were found to increase as a function of running speed in mice (Chen et al., 2011). One important possible reason for this difference concerns the anatomical differences between mice and rats (Ahmed and Mehta, 2009). In rats, the main source of cortical input to CA3 comes from layer II of the EC (Witter and Amaral, 2004). However, in mice, the main source of cortical input to CA3 is thought to arise from layer III of the EC (van Groen et al., 2003), which also projects directly to CA1. Therefore, in mice, CA1 is essentially resampling the activity of EC layer III twice: both directly and via CA3. Thus, the CA1 region of mice is probably less likely to show the differences in gamma frequency coherence with CA3 versus MEC that are seen in rats (Colgin et al., 2009), although this remains to be tested. If true, this might explain why mice are less likely to show gamma frequency shifts when running at faster speeds. We hypothesize that an important implication of these differences is that the place fields of mice are more likely to shift or change in size as a mouse runs at different speeds. This might also help to explain the consistently poorer performance of mice compared with rats on many hippocampus-dependent memory tasks (Whishaw, 1995). As discussed below, in rats, the systematic changes in hippocampal gamma frequency with speed might help to stabilize the position and size of place fields despite vast differences in running speeds across trials. 


\section{Possible functions of increased gamma frequency at increased speeds}

Montgomery and Buzsáki (2007) also showed that total gamma power increased at specific locations on the track where the rat was most likely to make decisions. This suggests that the total power in the gamma band can encode very different information from the frequency of gamma oscillations. The observation that increases in total hippocampal gamma power are correlated to decision making (Montgomery and Buzsáki, 2007) is consistent with similar roles for increased gamma power in the visual cortex (Womelsdorf et al., 2006). What, then, is the function of increased hippocampal gamma frequency? We propose the following hypothesis.

Many CA1 place cells encode each region of space (Wilson and McNaughton, 1993). These overlapping place cells have been shown to fire nearly synchronously within a $\sim 20 \mathrm{~ms}$ window, approximately corresponding to the period of a gamma cycle (Harris et al., 2003; Senior et al., 2008). This is immediately followed by the synchronous firing of the group of cells encoding the next point in space. These transitions between groups of cells have been described as internally generated cell-assembly sequences (Harris et al., 2003; Harris, 2005; Pastalkova et al., 2008; Senior et al., 2008). This concept of internally generated sequences has been suggested as a possible explanation for why many different place cells are sequentially activated as a rat runs in a fixed location on a running wheel (Czurkó et al., 1999; Pastalkova et al., 2008). Place cells are also seen in the absence of visual input (Quirk et al., 1990; Markus et al., 1994) and in blind rats (Save et al., 1998), suggesting an important role for the sequential activation of internally generated cell assemblies in generating place cells. If place cells are, at least partially, the result of internally generated sequences, how can place cells maintain their spatial specificity despite the rat running at very different speeds during each lap?

Put another way, when a rat runs faster, how can the hippocampal network complete the same spatial sequence of place cells in a shorter period of time? There are two possible solutions: it can either skip elements of the spatial sequence, or it can transition between each element of the sequence faster. We believe that the increased gamma frequencies at higher speeds might reflect the latter of these two solutions. Each gamma cycle represents the activation of one element in the cell-assembly sequence, and at faster speeds there are faster transitions between each element of the cell assembly (Senior et al., 2008; Maurer et al., 2012). These faster transitions might allow place cells to retain their spatial specificity despite faster running speeds, thus allowing the hippocampus to encode spatial information and memory independent of running speed, even in the absence of external cues.

Traub et al. (1996) observed a linear increase in gamma frequency with increasing feedforward drive to inhibitory interneurons in vitro. Consistently, we have observed an approximately linear increase in gamma frequency as a function of increasing speed, and as a function of the interneuron firing rates in vivo. Importantly, recent observations by Maurer et al. (2012) have shown a linear increase in the number of cell assemblies being encoded in a given period of time as a function of increasing speed. Thus, our results fit well with these previous findings, in that the linear increase in the number of cell assemblies activated per second would correlate with the linear increases in gamma frequency as a function of speed.

This process is crucially dependent on the fact that increased running speeds are accompanied by increased excitatory input to CA1. This increased input causes networks of interneurons and pyramidal cells to oscillate faster and leads to increases in gamma frequency (Traub et al., 1996; Börgers et al., 2005; Tiesinga and Sejnowski, 2009). CA1 probably receives this increased external drive due to the higher firing rates seen in CA3 (Diba and Buzsáki, 2008) and the MEC (Sargolini et al., 2006) at faster speeds. But what brain region provides the entorhinal cortex with an increased excitatory drive at higher speeds? An important next step is to follow the trail of this speed signal by analyzing the relationship between running speed, firing rate, and gamma frequency in every brain region thought to be involved in spatial navigation. This trail may very well lead all the way back to the vestibular system or visual system or both (Sharp et al., 1995; Knierim et al., 1996; Smith, 1997; Büttner-Ennever, 1999; Sekirnjak and du Lac, 2002; Wallace et al., 2002; Horii et al., 2004; Angelaki and Cullen, 2008; Zwergal et al., 2009).

\section{References}

Ahmed OJ (2010) Interpreting the rhythms of the hippocampus and neocortex. PhD thesis, Brown University.

Ahmed OJ, Mehta MR (2009) The hippocampal rate code: anatomy, physiology and theory. Trends Neurosci 32:329-338.

Angelaki DE, Cullen KE (2008) Vestibular system: the many facets of a multimodal sense. Annu Rev Neurosci 31:125-150.

Barlow JS (1964) Inertial navigation as a basis for animal navigation. J Theor Biol 6:76-117.

Best PJ, White AM, Minai A (2001) Spatial processing in the brain: the activity of hippocampal place cells. Annu Rev Neurosci 24:459-486.

Börgers C, Epstein S, Kopell NJ (2005) Background gamma rhythmicity and attention in cortical local circuits: a computational study. Proc Natl Acad Sci U S A 102:7002-7007.

Bragin A, Jand ó G, Nádasdy Z, Hetke J, Wise K, Buzsáki G (1995) Gamma $(40-100 \mathrm{~Hz})$ oscillation in the hippocampus of the behaving rat. J Neurosci 15:47-60.

Büttner-Ennever JA (1999) A review of otolith pathways to brainstem and cerebellum. Ann N Y Acad Sci 871:51-64.

Buzsáki G (2005) Theta rhythm of navigation: link between path integration and landmark navigation, episodic and semantic memory. Hippocampus 15:827-840.

Buzsáki G (2006) Rhythms of the brain. Oxford; New York: Oxford UP.

Buzsáki G, Draguhn A (2004) Neuronal oscillations in cortical networks. Science 304:1926-1929.

Buzsáki G, Horváth Z, Urioste R, Hetke J, Wise K (1992) High-frequency network oscillation in the hippocampus. Science 256:1025-1027.

Cardin JA, Carlén M, Meletis K, Knoblich U, Zhang F, Deisseroth K, Tsai LH, Moore CI (2009) Driving fast-spiking cells induces gamma rhythm and controls sensory responses. Nature 459:663-667.

Chen Z, Resnik E, McFarland JM, Sakmann B, Mehta MR (2011) Speed controls the amplitude and timing of the hippocampal gamma rhythm. PLoS One 6:e21408.

Colgin LL, Denninger T, Fyhn M, Hafting T, Bonnevie T, Jensen O, Moser MB, Moser EI (2009) Frequency of gamma oscillations routes flow of information in the hippocampus. Nature 462:353-357.

Csicsvari J, Jamieson B, Wise KD, Buzsáki G (2003) Mechanisms of gamma oscillations in the hippocampus of the behaving rat. Neuron 37:311-322.

Czurk ó A, Hirase H, Csicsvari J, Buzsáki G (1999) Sustained activation of hippocampal pyramidal cells by 'space clamping' in a running wheel. Eur J Neurosci 11:344-352.

Diba K, Buzsáki G (2008) Hippocampal network dynamics constrain the time lag between pyramidal cells across modified environments. J Neurosci 28:13448-13456.

Fox SE, Ranck JB Jr (1981) Electrophysiological characteristics of hippocampal complex-spike cells and theta cells. Exp Brain Res 41:399-410.

Fries P (2009) Neuronal gamma-band synchronization as a fundamental process in cortical computation. Annu Rev Neurosci 32:209-224.

Geisler C, Robbe D, Zugaro M, Sirota A, Buzsáki G (2007) Hippocampal place cell assemblies are speed-controlled oscillators. Proc Natl Acad Sci U S A 104:8149-8154.

Gregoriou GG, Gotts SJ, Zhou H, Desimone R (2009) High-frequency, long-range coupling between prefrontal and visual cortex during attention. Science 324:1207-1210. 
Harris KD (2005) Neural signatures of cell assembly organization. Nat Rev Neurosci 6:399-407.

Harris KD, Csicsvari J, Hirase H, Dragoi G, Buzsáki G (2003) Organization of cell assemblies in the hippocampus. Nature 424:552-556.

Horii A, Russell NA, Smith PF, Darlington CL, Bilkey DK (2004) Vestibular influences on CA1 neurons in the rat hippocampus: an electrophysiological study in vivo. Exp Brain Res 155:245-250.

Jarvis MR, Mitra PP (2001) Sampling properties of the spectrum and coherency of sequences of action potentials. Neural Comput 13:717-749.

Kajikawa Y, Schroeder CE (2011) How local is the local field potential? Neuron 72:847-858.

Knierim JJ, Skaggs WE, Kudrimoti HS, McNaughton BL (1996) Vestibular and visual cues in navigation: a tale of two cities. Ann N Y Acad Sci 781:399-406.

Leutgeb S, Ragozzino KE, Mizumori SJ (2000) Convergence of head direction and place information in the CA1 region of hippocampus. Neuroscience 100:11-19.

Markus EJ, Barnes CA, McNaughton BL, Gladden VL, Skaggs WE (1994) Spatial information content and reliability of hippocampal CA1 neurons: effects of visual input. Hippocampus 4:410-421.

Maurer AP, Burke SN, Lipa P, Skaggs WE, Barnes CA (2012) Greater running speeds result in altered hippocampal phase sequence dynamics. Hippocampus 22:737-747.

McFarland WL, Teitelbaum H, Hedges EK (1975) Relationship between hippocampal theta activity and running speed in the rat. J Comp Physiol Psychol 88:324-328.

McNaughton BL, Barnes CA, O'Keefe J (1983) The contributions of position, direction, and velocity to single unit activity in the hippocampus of freely-moving rats. Exp Brain Res 52:41-49.

McNaughton BL, Barnes CA, Gerrard JL, Gothard K, Jung MW, Knierim JJ, Kudrimoti H, Qin Y, Skaggs WE, Suster M, Weaver KL (1996) Deciphering the hippocampal polyglot: the hippocampus as a path integration system. J Exp Biol 199:173-185.

McNaughton BL, Battaglia FP, Jensen O, Moser EI, Moser MB (2006) Path integration and the neural basis of the 'cognitive map'. Nat Rev Neurosci 7:663-678.

Mizumori SJ, Williams JD (1993) Directionally selective mnemonic properties of neurons in the lateral dorsal nucleus of the thalamus of rats. J Neurosci 13:4015-4028.

Montgomery SM, Buzsáki G (2007) Gamma oscillations dynamically couple hippocampal CA3 and CA1 regions during memory task performance. Proc Natl Acad Sci U S A 104:14495-14500.

Montgomery SM, Sirota A, Buzsáki G (2008) Theta and gamma coordination of hippocampal networks during waking and rapid eye movement sleep. J Neurosci 28:6731-6741.

Nitz D, McNaughton B (2004) Differential modulation of CA1 and dentate gyrus interneurons during exploration of novel environments. J Neurophysiol 91:863-872.

O’Keefe J, Dostrovsky J (1971) The hippocampus as a spatial map. Preliminary evidence from unit activity in the freely-moving rat. Brain Res 34:171-175.

Pastalkova E, Itskov V, Amarasingham A, Buzsáki G (2008) Internally generated cell assembly sequences in the rat hippocampus. Science 321:1322-1327.

Quirk GJ, Muller RU, Kubie JL (1990) The firing of hippocampal place cells in the dark depends on the rat's recent experience. J Neurosci 10:2008-2017.

Sabolek HR, Penley SC, Hinman JR, Bunce JG, Markus EJ, Escabi M, Chrobak JJ (2009) Theta and gamma coherence along the septotemporal axis of the hippocampus. J Neurophysiol 101:1192-1200.

Sargolini F, Fyhn M, Hafting T, McNaughton BL, Witter MP, Moser MB,
Moser EI (2006) Conjunctive representation of position, direction, and velocity in entorhinal cortex. Science 312:758-762.

Save E, Cressant A, Thinus-Blanc C, Poucet B (1998) Spatial firing of hippocampal place cells in blind rats. J Neurosci 18:1818-1826.

Sekirnjak C, du Lac S (2002) Intrinsic firing dynamics of vestibular nucleus neurons. J Neurosci 22:2083-2095.

Senior TJ, Huxter JR, Allen K, O’Neill J, Csicsvari J (2008) Gamma oscillatory firing reveals distinct populations of pyramidal cells in the CA1 region of the hippocampus. J Neurosci 28:2274-2286.

Sharp PE, Blair HT, Etkin D, Tzanetos DB (1995) Influences of vestibular and visual motion information on the spatial firing patterns of hippocampal place cells. J Neurosci 15:173-189.

Shin J, Talnov A (2001) A single trial analysis of hippocampal theta frequency during nonsteady wheel running in rats. Brain Res 897:217-221.

Singer W (1993) Synchronization of cortical activity and its putative role in information processing and learning. Annu Rev Physiol 55:349-374.

Slawińska U, Kasicki S (1998) The frequency of rat's hippocampal theta rhythm is related to the speed of locomotion. Brain Res 796:327-331.

Smith PF (1997) Vestibular-hippocampal interactions. Hippocampus 7: $465-471$.

Squire LR (1992) Memory and the hippocampus: a synthesis from findings with rats, monkeys, and humans. Psychol Rev 99:195-231.

Taube JS (1995) Head direction cells recorded in the anterior thalamic nuclei of freely moving rats. J Neurosci 15:70-86.

Taube JS (2007) The head direction signal: origins and sensory-motor integration. Annu Rev Neurosci 30:181-207.

Taube JS, Muller RU, Ranck JB Jr (1990a) Head-direction cells recorded from the postsubiculum in freely moving rats. I. Description and quantitative analysis. J Neurosci 10:420-435.

Taube JS, Muller RU, Ranck JB Jr (1990b) Head-direction cells recorded from the postsubiculum in freely moving rats. II. Effects of environmental manipulations. J Neurosci 10:436-447.

Tiesinga PH, Sejnowski TJ (2009) Cortical enlightenment: are attentional gamma oscillations driven by ING or PING?. Neuron 63:727-732.

Tort AB, Komorowski RW, Manns JR, Kopell NJ, Eichenbaum H (2009) Theta-gamma coupling increases during the learning of item-context associations. Proc Natl Acad Sci U S A 106:20942-20947.

Traub RD, Whittington MA, Colling SB, Buzsáki G, Jefferys JG (1996) Analysis of gamma rhythms in the rat hippocampus in vitro and in vivo. J Physiol 493: 471-484.

van Groen T, Miettinen P, Kadish I (2003) The entorhinal cortex of the mouse: organization of the projection to the hippocampal formation. Hippocampus 13:133-149.

Wallace DG, Hines DJ, Pellis SM, Whishaw IQ (2002) Vestibular information is required for dead reckoning in the rat. J Neurosci 22:10009-10017.

Whishaw IQ (1995) A comparison of rats and mice in a swimming pool place task and matching to place task: some surprising differences. Physiol Behav 58:687-693.

Whishaw IQ, McKenna JE, Maaswinkel H (1997) Hippocampal lesions and path integration. Curr Opin Neurobiol 7:228-234.

Wilson MA, McNaughton BL (1993) Dynamics of the hippocampal ensemble code for space. Science 261:1055-1058.

Witter MP, Amaral DG (2004) Hippocampal formation. In: The rat nervous system, Ed 3 (Paxinos G, ed), pp xvii, 1309 p. Amsterdam; Boston: Elsevier Academic.

Womelsdorf T, Fries P, Mitra PP, Desimone R (2006) Gamma-band synchronization in visual cortex predicts speed of change detection. Nature 439:733-736.

Zwergal A, Strupp M, Brandt T, Büttner-Ennever JA (2009) Parallel ascending vestibular pathways: anatomical localization and functional specialization. Ann N Y Acad Sci 1164:51-59. 